\title{
OSCE-A New Assessment Method for Pharmaceutical Education
}

\author{
Amit Vanka1, Othman Wali², Butchi Raju Akondi ${ }^{3,{ }^{*},}$, Shanthi Vanka1, Sreeja Ravindran ${ }^{4}$ \\ ${ }^{1}$ Department of Preventive Dentistry, Ibn Sina National College for Medical Studies, Jeddah, SAUDI ARABIA. \\ ${ }^{2}$ Vice Dean, Dentistry Program, Ibn Sina National College for Medical Studies, Jeddah, SAUDI ARABIA. \\ ${ }^{3}$ Department of Clinical Pharmacy and Pharmacology, Ibn Sina National College for Medical Studies, Jeddah, SAUDI ARABIA. \\ ${ }^{4}$ Former Faculty, Department of Oral Pathology, Ibn Sina National College for Medical Studies, Jeddah, SAUDI ARABIA.
}

\begin{abstract}
More reliable and validated method of assessment is the need of the hour for better summative evaluation of the students of pharmaceutical sciences. Competency or outcome based education models rely heavily on assessment methods. The objective structured clinical examination (OSCE) fits in to the gap and fulfills the requirement of testing the clinical/practical skills in more objective way. This review explores steps in planning and implementing an OSCE for institutes as well as high stakes exams. Organizations like Pharmacy Council of India and All India Council for Technical Education can develop guidelines to implement OSCE.
\end{abstract}

Key words: OSCE, Assessment, Pharmaceutical Education, Clinical Skills, Summative Evaluation.

\section{INTRODUCTION}

Outcome and competency-based education models are being widely accepted and implemented. The concept of competencies relies heavily on the development of assessment methods that are reliable, valid, feasible and positively impacting learning in the education system. ${ }^{1}$ Assessment in medical education has evolved from the traditional pen and paper tests to a more holistic evaluation spectrum that includes problem-based learning, faculty global ratings and checklists, standardized patients, and team-based learning. ${ }^{2}$ As opposed to the procedural emphasis in medical field, pharmacists must rely almost entirely upon speaking, listening, reading, writing, and observing to gather data, ${ }^{3}$ and hence assessment in this context differs considerably.

One of the widely used tools to assess clinical or practical competency, particularly in undergraduate education, is the objective structured clinical examination (OSCE). Though it was introduced in 1975 as an assessment method in a medical school, ${ }^{4}$ the OSCE today is the principle method for assessment across the various health professions. Around the 1970's the regulatory body for pharmacy practice in British Columbia, Canada also began using standardized practice problems and patient simulations in an OSCE format as a method of evaluating entry-to-practice and continuing competency of its pharmacist members. ${ }^{5}$ In 1996, the Ontario College of Pharmacists (the regulatory/licensing body for pharmacy practice in Canada's largest province) instituted an OSCE as part of its compulsory Quality Assurance and Practice Review program for all practicing pharmacists. ${ }^{5}$ In recent times OSCE is used to test several entry level competencies that have been identified in Canada. ${ }^{6}$ Nevertheless, the usage of OSCE in Pharm D programs or licensure exam in India continues to lag behind counterparts in other countries ${ }^{7}$ due to a multitude of barriers.

The OSCE method, as used today, has evolved into a flexible testing approach that
Submission Date: 18-4-18; Revision Date: 15-5-18; Accepted Date: 01-06-18

DOI:10.5530/ijper.52.4s.68 Correspondence: Dr. Akondi Butchi Raju, Department of Clinical Pharmacy and Pharmacology, Ibn Sina National College for Medical Studies, Jeddah, SAUDI ARABIA

Phone: +966 557945448 E-mail: drraju2020@gmail. com

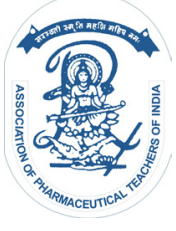

www.ijper.org 
can incorporate standardized patients as well as observer ratings, short written tests, and other methods used to provide a comprehensive clinical evaluation of history taking, physical examination, and communication skills. OSCEs can therefore effectively assess psychomotor, cognitive and affective skills. ${ }^{8}$ In the broad sense, OSCE implies a class of examinations that use stations to measure performance. Other variants and terms used include Objective Structured Practical Examination (OSPE); Objective Structured Long Examination Record (OSLER); Group Objective Structured Clinical Examination (GOSCE). Never the less, all these examinations are modified such that they may be designed for a specific purpose but retain all the characteristics of the original OSCE. ${ }^{8}$ Specific OSCE's have been developed for pharmacy such as P-OSCE to test abilities based outcomes from pharmacy program. ${ }^{?}$

\section{How to conduct an OSCE}

A contemporary definition of an OSCE would include the following elements. ${ }^{10}$

1. A circuit of focused clinical problems, not necessarily arranged in a related fashion

2. Learners simultaneously progress through stations

3. Some stations include standardized patients (i.e. actors) that simulate real patient presentations

4. Scoring includes direct observation by a clinical expert

5. Scoring tools use a variation of global response scores or checklists.

\section{Purpose of the exam}

OSCE is used for both summative and formative assessments. OSCE as formative assessment is useful in providing feedback to the students and participation in an OSCE was found to improve the quality of the learning experiences as well as performance in subsequent examinations. ${ }^{11}$ OSCEs can identify low achieving students, particularly in the clinical arena, early on in their program.

Overall the impact of OSCE for summative assessments on student performance is a positive one. High-stakes OSCE is an appropriate assessment for the curriculum, complementing the OSCEs embedded in courses. Moreover, the OSCE complements, but does not replace, the traditional written licensing exam used to assess clinical knowledge to ensure entry-level practitioners meet standards of practice for the protection of the public. $^{12}$

\section{Decide what to test}

Some of the core competencies that need to be evaluated in pharmacy education include: professional and ethical practice, communication, collaboration and selfmanagement, leadership and management, review and supply prescribed medicines, prepare pharmaceutical products, deliver primary and preventive health care, promote and contribute to optimal use of medicines and critical analysis, research and education. ${ }^{13}$ The core advantage of OSCE is being able to assess student's performance across various domains of learning wherein performance denotes grades of the candidates as novice, advanced beginner, competent, proficient or experts in various competencies. ${ }^{14}$ In areas of pharmacy where students are exposed to patient management, OSCE assesses the higher levels of miller's learning pyramid and demonstrates readiness of the learner to practice (Figure 1).

The OSCE should be designed to assess certain competencies or skills which are not possible to be assessed using traditional pen and paper or computer based testing methods. The structured approach is an obvious advantage: nevertheless, there have been criticisms that the OSCE risks the compartmentalization of these skills (performance of skills in isolation) for the purposes of assessment. ${ }^{15}$ Besides, there is an ever prevalent risk that students may concentrate more on passing the OSCE rather than attempt to gain the respective skills and improve their actual clinical performance. This in turn can potentially decrease the educational impact of OSCE.

\section{Allocation of resources}

Success of OSCE heavily depends on the allocation of resources. Where an OSCE is conducted within an

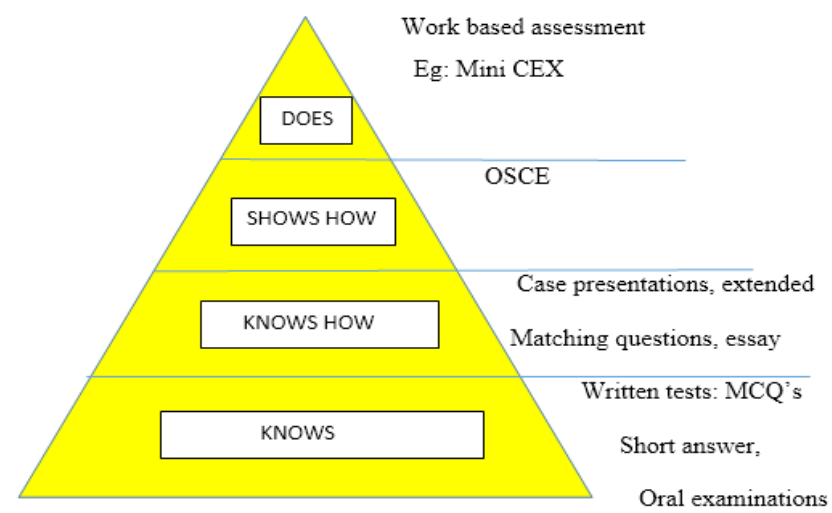

Figure 1: Various assessment tools and their correlation with millers pyramid of learning.

(MCQs: Multiple choice questions, OSCE: Objective structured clinical examination, Mini CEX: Clinical Evaluation Exercise). 
institution and used across all levels of the program, it becomes a cost effective tool due to the utilization of existing resources from within the institute, whereas an OSCE that is administered in a special facility designed for the purpose, is significantly costly, labor intensive or even prohibitive. ${ }^{8}$

\section{Developing a blueprint}

The blueprint is a template that is used to guide development of OSCE stations to ensure the tasks and problems depicted in simulations are relevant to practice and capture important elements of patient care. ${ }^{12}$ The content sampling specifications, or blueprint, of an exam should be carefully developed to ensure that the sample cases for any one test form represents the broad scope of content and domains to be assessed..$^{16}$ When used for high stakes examinations, a blueprint that outlines competencies and skills of entry-level pharmacists to be tested, the number of stations in the OSCE and the testing time, needs to be determined.

\section{Development of stations and item construction}

Stations should be based on everyday scenarios from pharmacy practice with alignment with the learning outcomes or competencies. While introducing the assessment into an institute or a council for licensing, an OSCE committee can be set up to collect data from practitioners and other stakeholders and deliberate upon the content and domains to be tested. Pre-testing stations from previous editions of the examination can help determine how long chosen competencies take to test effectively. ${ }^{17}$ The station numbers and profile can be also be ascertained using formative OSCEs with a limited number of stations. When utilized in higher levels of the program, it is advisable to include material covered elsewhere in the module or year of study, such that the students had come across the knowledge content previously. ${ }^{18}$ The item construction should provide enough information to guide the examinee to the required task, but not too little.

The station profile should include the condition, time required to complete task, the domain and competence tested and proposal of the suitable examiner. ${ }^{17}$ Majority of the stations used in OSCE are of the active type, manned by both a real/ standardized patient and an examiner. These stations may also include face to face or telephone communication with the examiner who plays the role of a patient or a healthcare professional; and written stations, which involve a short problem or questions such as dosage calculations. Other types of stations include 'preparation stations' that provides instructions for the next station, so that the candidate is fully aware of the task which he/she will be asked to complete at the next station. A variable number of 'Rest Stations' are included for candidates to review their answer sheets from previous stations. ${ }^{19}$

Each station is designed to last from 5 to $7 \mathrm{~min}$. No significant difference has been observed between dependability and generalizability coefficients between the 15 -station form of the exam and the 20-station form. Hence a range of 12-16 stations may adequately serve the needs of an OSCE exam. ${ }^{12}$ Nevertheless, studies are questioning the need for OSCEs to necessarily include large case banks to reach acceptable levels of reliability and suggest site specific decision studies. ${ }^{20}$

\section{Preparing scoring checklists}

A criterion based checklist or analytic tool is frequently used to mark OSCEs. Checklists generally utilize a binary marking scale (achieved or not achieved). ${ }^{21}$ The checklists are weighted based on relative importance as decided by the experts and the purpose of the exam. Recently, global rating scales have used either individually or in combination with checklists. ${ }^{22}$ The analytic global rating showed substantially higher internal consistency and better psychometric properties than did the checklists. ${ }^{23}$ A 4 point rating scale can be used which allows the overall quality of the student's performance to be assessed.

\section{Standardized patients}

Most OSCEs have come to rely heavily on standardized patients (SPs) a term that needs to be differentiated from simulated patients (also abbreviated as SP). Standardized patients are actors or other individuals trained to portray a realistic patient with a particular disease or condition, in a consistent manner, thus affording hands-on testing of students. On the other hand, a simulated patient merely simulates the role of a patient and need not necessarily have undergone specific training. ${ }^{8}$ According to opinions from both students and practitioners, a pharmacy OSCE format, requiring students to demonstrate the ability to perform professional pharmacy practice competencies utilizing SPs, provides a positive learning experience. ${ }^{24}$ The integration of virtual patients in OSCE reveals that this assessment method is efficient and practical in many aspects since it provides the test taker with a much closer real-life clinical encounter. Although it is in many ways more difficult, it also provides for better "learning from mistakes" opportunities for test-takers. ${ }^{25}$

\section{Instructions for students}

Candidate instructions must be clear, precise and state the specific task, skill or their combination to be dem- 
onstrated. Instructions should provide clear instructions on the division of marks and overall guide the students through the various stations of OSCE. ${ }^{17}$

\section{Instructions to examiner}

Explicit instructions should always be provided for the examiners including the station profile, the item construct and the scoring criteria. ${ }^{17}$ It is a healthy practice to conduct workshops for faculty participating in OSCE for the first time. The faculty may also need to be calibrated to avoid intra and inter examiner variability. A common set of instructions needs to be developed for both examiner and students to serve as a reference guide for both. ${ }^{17}$

\section{Pilot test}

It is essential that additional to the efforts invested in development of OSCE a pilot run be conducted. The logistics of implementing an OSCE can be reviewed, besides gathering valuable input from faculty and colleagues including experiences such as role playing the script of standardized patients with colleague. ${ }^{16}$

\section{Reliability and validity of OSCE (quality assurance)}

In essence OSCE attempts to eliminate subjective bias (objective) and the examination is conducted in such a way that the content of the examination and the competences to be tested are planned carefully in advance (structured). ${ }^{26}$

Results from a meta-analysis ${ }^{27}$ report that the reliability of an OSCE exam is moderate. Several key elements affect the reliability scores and should be noted by all educators. In the OSCE, a measurement error can be attributed to the following: 1) stations, 2) standardized patients, 3) examiners, 4) scenarios (if the OSCE is conducted at multiple sites), and 5) occasion effects (if the OSCE is conducted at different times) ${ }^{28}$ Utilizing two assessors instead of one, increasing the number of stations and an appropriate test length has been found to improve the reliability. ${ }^{29}$

Highly valid scores are imperative, particularly if OSCE is being utilized to make high stakes decisions. Studies have been equivocal, with some demonstrating high validity evidence as compared to other methods of testing. Validity has been demonstrated for development of content, rigorous control of the response process, internal structure and demonstration of acceptable interpreter agreement. ${ }^{30}$ Others have demonstrated less than desirable validity scores compared to multiple choice questions. ${ }^{31}$ The results can be at least partially be explained by the fact that OSCE is often compared to assessment tools for specific domains. ${ }^{32,33}$ In contrast
OSCE assesses competencies across multiple domains. Overall, modest validity can be achieved with OSCE.

\section{CONCLUSION}

The OSCE scores over the traditional assessment methods due to the reliability and assessment at higher level on the miller's pyramid. Both patient and learner safety coupled with an improved quality of learning outcome achievement are the key benefits of the OSCE. However, optimal benefits can be gained by judicious planning, training and avoiding overreliance on OSCE as a panacea for all evils associated with assessment methods.

\section{ACKNOWLEDGEMENT}

Authors express deep gratitude to Ibn Sina National College for Medical Studies, Jeddah for providing exposure to learn newer teaching, learning and assessment methods in Pharmaceutical Education.

\section{CONFLICT OF INTEREST}

None of the authors have any personal or financial conflicts of interest.

\section{ABBREVIATIONS}

OSCE: Objective structured clinical examination; OSLER: Objective Structured Long Examination Record; GOSCE: Group Objective Structured Clinical Examination.

\section{REFERENCES}

1. GMC | Home [Internet]. Gmc-uk.org. 2018 [cited 1 April 2018]. Available from: https://www.gmc-uk.org/

2. Epstein R. Assessment in Medical Education. New England Journal of Medicine. 2007;356(4):387-96.

3. Munoz LQ, O'Byrne C, Pugsley J, Austin Z. Reliability, validity, and generalizability of an objective structured clinical examination (OSCE) for assessment of entry-to-practice in pharmacy. Pharm Educ. 2005;5(1):33-43.

4. Harden RM, Stevenson M, Downie WW, Wilson GM. Assessment of clinical competence using objective structured examination. $\mathrm{Br}$ Med $\mathrm{J}$. 1975;1(5955):447-51.

5. Kirton S, Kravitz L. Objective Structured Clinical Examinations (OSCEs) Compared With Traditional Assessment Methods. American Journal of Pharmaceutical Education. 2011;75(6):111.

6. Welcome to PEBC Pharmacists Website [Internet]. Pebc ca. 2018. [cited 1 April 2018]. Available from: https://www.pebc.ca/index.php/ci_id/3374/ la_id/1.htm

7. Rajiah K, Veettil SK. Objective structured clinical examination in pharm D and clinical pharmacy courses in India; a rising need to acquaint? Indian J Pharm Educ Res. 2013;47:1-6.

8. Shumway JM, Harden RM. Association for Medical Education in Europe (AMEE) Education Guide No 25: The assessment of learning outcomes for the competent and reflective physician. Med Teach. 2003;25(6):569-84. 
9. Monaghan MS, Vanderbush RE, Gardner SF, Schneider EF, Grady AR, McKay AB. Standardized patients: An ability-based outcomes assessment for the evaluation of clinical skills in traditional and nontraditional education. Am J Pharm Educ. 1997;61(4):337-44.

10. Anon. A systematic review of the reliability of objective structured clinical examination scores. 2018. [online] Available from:http://www.royalcollege.ca/ rcsite/documents/canmeds/keylime-ep28-js-brannick-et-al-e.pdf [Accessed 27 Apr. 2018].

11. Bernard A, Ceccolini G, Feinn R, Rockfeld J, Rosenberg I, Thomas L, et al. Medical students review of formative OSCE scores, checklists, and videos improves with student-faculty debriefing meetings. Medical Education Online. 2017;22(1):1324718.

12. Austin Z, O'Byrne C, Pugsley J, Munoz L. Development and Validation Processes for an Objective Structured Clinical Examination (OSCE) for Entry-to-Practice Certification in Pharmacy: The Canadian Experience. American Journal of Pharmaceutical Education. 2003;67(3):76.

13. Sztar R, Friary R, Armon B, Neel P, Hogan B. Competency Standards Complete Australia | Pharmacy | Competence (Human Resources). 2018. [online] Scribd. Available at: https://www.scribd.com/document/371212256/ Competency-Standards-Complete-Australia [Accessed 27 Apr. 2018].

14. Khan K, Ramachandran S. Conceptual Framework for Performance Assessment: Competency, Competence and Performance in the Context of Assessments in Healthcare -Deciphering the Terminology. Med Teach. 2012:34(11):920-8.

15. Shirwaikar A. Objective structured clinical examination (OSCE) in pharmacy education - a trend. Pharm Pract. 2015;13(4):627.

16. Medical council of Canada: Guidelines for the development of objective structured clinical examination (OSCE) cases. 2013. Available at

17. http://mcc.ca/media/OSCE-Booklet-2014.pdf Accessed January. 2018.

18. Saudi Commission for Health Specialties: OSCE manual. 2014. Available at

19. https://www.scfhs.org.sa/en/Media/OtherPublications/Documents/ OSCEMANUAL Accessed January, 2018.

20. Evans BW, Alinier G, Kostrzewski A, Lefteri KA, Dhillon S. Development and design of objective structured clinical examinations (OSCE) in undergraduate pharmacy education in a new School of Pharmacy in England. Curr Pharm Teach Learn. 2011:3(3):216-23.

21. Sturpe DA. Objective Structured Clinical Examinations in Doctor of Pharmacy Programs in the United States. Am J Pharm Educ. 2010;74(8):148.
22. Blood AD, Park YS, Lukas RV, Brorson JR. Neurology objective structured clinical examination reliability using generalizability theory. Neurology. 2015;85(18):1623-9.

23. Hodges B, Regehr G, McNaughton N, Tiberius R, Hanson M. OSCE checklists do not capture increasing levels of expertise. Acad Med. 1999;74(10):1129.

24. Read EK, Bell C2, Rhind S, Hecker KG. The use of global rating scales for OSCEs in veterinary medicine. PLoS One. 2015;10(3):1-10.

25. Veettil SK, Rajiah K. Impact of Task-based Checklist Scoring and Two Domains Global Rating Scale in Objective Structured Clinical Examination of Pharmacy Students. Indian J Pharm Educ Res. 2016:50(1):17-23.

26. Monaghan MS, Vanderbush RE, Gardner SF, Schneider EF, Grady AR, McKay AB. Standardized patients: An ability-based outcomes assessment for the evaluation of clinical skills in traditional and nontraditional education. Am J Pharm Educ.1997;61(4):337-44.

27. Lin CW, Chang EH, Clinciu DL, Peng YT, Huang WC, Wu CC, et al. Using modified information delivery to enhance the traditional pharmacy OSCE program at TMU - a pilot study. Comput Methods Programs Biomed. 2018;158:147-52.

28. Harden RM, What is an OSCE? Med Teach.1988;10(1):19-22.

29. Brannick M, Erol-Korkmaz H, Prewett M. A systematic review of the reliability of objective structured clinical examination scores. Med Educ. 2011;45(12):1181-9.

30. Trejo-Mejía JA, Sánchez-Mendiola M, Méndez-Ramírez I, Martínez-González A. Reliability analysis of the objective structured clinical examination using generalizability theory. Med Educ Online. 2016;21(1):31650.

31. ACGME, ABMS. Toolbox of Assessment Methods. A Product of the Joint Initiative. Accreditation Council for Graduate Medical Education (ACGME) Outcomes Project. American Board of Medical Specialties (ABMS). 2000. Version 1.1, September 2000. [Cited 20 Nov 2017]

32. Auewarakul C, Downing SM, Jaturatamrong U, Praditsuwan R. Sources of validity evidence for an internal medicine student evaluation system: An evaluative study of assessment methods. Med Educ. 2005;39(3):276-83.

33. Ram P, Van der Vleuten C, Rethans JJ, Schouten B, Homba S, Grol R. Assessment in general practice: The predictive value of written knowledge tests and a multiple-station examination for actual medical performance in daily practice. Med Educ. 1999;33(3):197-203.

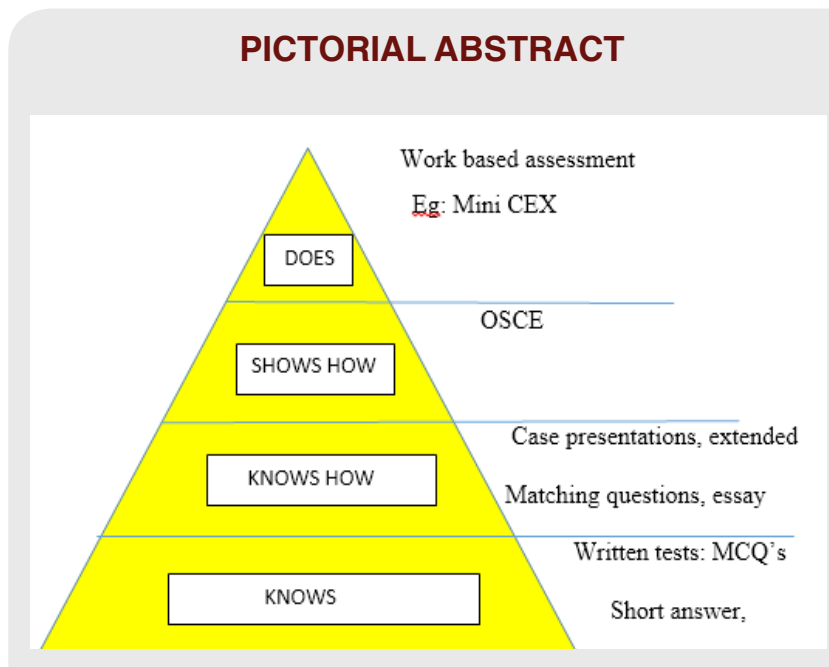

\section{SUMMARY}

- OSCE is an essential assessment tool that is currently underutilized in India. We have provided a basic step wise approach to implement OSCE for undergraduate pharmaceutical education. We hope this review can provide impetus to discuss OSCE in the academic circles.

\section{About Authors}

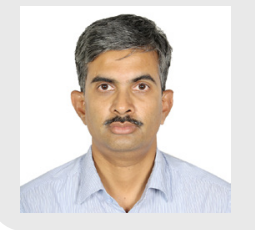

Dr. Amit Vanka: Received his masters in dentistry from prestigious Manipal University, India and currently working as Associate Professor of pedodontics and chairman of department. He studied the evolution of assessment methods in medical education and he is most efficient practioner of newer methods of teaching, learning and assessment. 


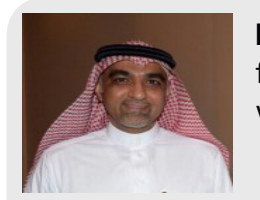

Dr. Othman Wali: Received his Master's Degree in dentistry from Sweden and he is having fellowship in advanced Perio-Prostho and Dental implants from United States. Currently he is working as vice dean and practices efficient teaching, learning and assessment methods.

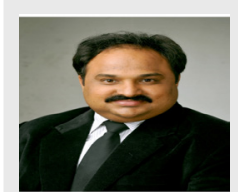

Dr. Akondi Butchi Raju: Obtained his PhD from Andhra University, India and currently working as Assistant Professor in Ibn Sina National College for Medical Studies, Jeddah, Saudi Arabia. Dr. Raju is Pharmacologist working in the area of reproduction and central nervous system related drugs. He is enthusiastic about newer methods of teaching, learning and assessment.

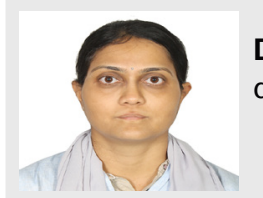

Dr. Shanthi Vanka: Trained dentist and health educationist. Received her master's in public health dentistry from India and currently involved in quality aspects of health care education.

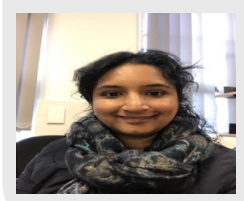

Dr. Sreeja Ravindran: Practicing dentist and worked as Assistant Professor in Ibn Sina National College for Medical Studies. Initiated innovative methods of feedback collection from students. Enthusiastic practioners of newer method of assessment.

Cite this article: Vanka A, Wali O, Akondi BR, Vanka S, Ravindran S. OSCE-A New Assessment Method for Pharmaceutical Education. Indian J of Pharmaceutical Education and Research. 2018;52(4S):S1-S6. 